\title{
Philosophiques
}

\section{Gilles Lane, Pouvoir, justice et non-mépris, Montréal, VLB éditeur, coll. " Enjeux philosophiques », 1989, 210 p.}

\section{Yves Roy}

Volume 16, numéro 2, automne 1989

URI : https://id.erudit.org/iderudit/027088ar

DOI : https://doi.org/10.7202/027088ar

Aller au sommaire du numéro

Éditeur(s)

Société de philosophie du Québec

ISSN

0316-2923 (imprimé)

1492-1391 (numérique)

Découvrir la revue

Citer ce compte rendu

Roy, Y. (1989). Compte rendu de [Gilles Lane, Pouvoir, justice et non-mépris,

Montréal, VLB éditeur, coll. « Enjeux philosophiques », 1989, 210 p.]

Philosophiques, 16(2), 405-407. https://doi.org/10.7202/027088ar d'utilisation que vous pouvez consulter en ligne.

https://apropos.erudit.org/fr/usagers/politique-dutilisation/ 
PHILOSOPHIQUES, Vol. XVI, Numéro 2, Automne 1989

\section{COMPTES RENDUS}

GILles lane, Pouvoir, justice et non-mépris, Montréal, VLB éditeur, coll. «Enjeux philosophiques », 1989, 210 p.

$$
\text { par Yves Roy }
$$

Dans un article devenu célèbre, "La théorie politique existe-t-elle? » (dont l'original est paru en français dans la Revue française de science politique, vol. XI, $\left.\mathrm{n}^{\prime \prime} 2,1961\right)$, Isaiah Berlin soutient qu'aucune œuvre décisive de philosophie politique n'est parue au $\mathrm{XX}^{\mathrm{e}}$ siècle.

Dans leur introduction à Pbilosopby, Politics and Society ( $5^{\text {th }}$ Series), Peter Laslett et James Fishkin affirment qu'en 1978, cette affirmation n'est plus vraie: désormais il faudra compter avec $A$ Theory of Justice de John Rawls et Anarcby, State, and Utopia de Robert Nozick. À ces titres, il faut maintenant ajouter le dernier livre de Gilles Lane, Pouvoir, justice et nonmépris.

Cet ouvrage majeur de philosophie politique fait suite à une autre œuvre non moins importante en éthique, $S i$ les marionnettes pouvaient choisir (Montréal : Éditions de l'Hexagone, coll. «Positions philosophiques », 1983), dans laquelle l'auteur expose sa théorie de la liberté, qui sert de noyau central à l'arrière-plan de son nouvel ouvrage.

D'entrée de jeu, Lane énonce l'intuition qui l'a guidé :

$[\ldots]$ il ne devrait pas être nécessaire $[\ldots]$ que chacun sache si tel comportement est en lui-même juste ou injuste, ou si ses conséquences seront vraiment les moins dommageables possible, pour être en mesure de savoir si lui-même commettrait une injustice en se conduisant de cette façon. Il ne devrait pas non plus être nécessaire, pour savoir cela, que chacun attende l'accord de tous les autres, ni même celui du plus grand nombre de penseurs ou de spécialistes. Car c'est souvent tout de suite $[\ldots]$ qu'il faudrait pouvoir décider soi-même quoi faire, et donc savoir assez bien quel choix serait juste ou injuste (10).

Sa méthode : l'explicitation de l'implicite (10); sa visée : savoir ce qu'on peut, sans illusion, attendre de la vie en société ou des pouvoirs politiques (11).

Ce qu'on attend généralement d'un gouvernement, «c'est qu'il s'efforce d'augmenter les possibilités d'une vie plus heureuse pour tous les membres 
de la société »(15) et, peut-être pour cette raison, qu'il diminue les injustices sans en commettre lui-même.

Or, ces attentes ne sont pas réalistes, car aucun gouvernement ne peut les combler, ne serait-ce que parce qu'aucun gouvernement - ni même aucun individu - ne peut à bon droit prétendre connaître les conséquences de ses interventions. Cependant, les analyses de Lane amènent à conclure que tout gouvernement n'est pas inutile, s'il adopte comme principale visée la fonction de "catalyseur» en vue de favoriser l'entraide sociale.

Les articulations majeures de la démarche de l'auteur sont fonction de trois notions (injustice, vie fondamentalement heureuse, entraide sociale) elles-mêmes définies en fonction de la liberté.

Contrairement à ce que l'on affirme très souvent, une injustice n'est pas, en soi, un dommage grave qui serait subi. En effet, un séisme pourrait entraîner des dommages fort graves, mais il n'y aurait pas lieu de parler d'injustice. De plus, quelqu'un peut causer des dommages à d'autres individus tout en le déplorant (il suffit qu'il ne puisse faire autrement). II n'y aurait alors pas d'injustice. «Il y aurait |...] injustice non pas lorsque des dommages [... sont causés à autrui, mais seulement lorsqu'il y a libre choix d'en causer " (50). En d'autres termes, les dommages ne seraient que des signes (parfois très éloquents) d'un mépris à l'égard d'autrui. C'est ce mépris qui constituerait en lui-même l'injustice :

La condition nécessaire, et suffisante, pour qu'il y ait une injustice de commise, c'est une attitude particulière à l'égard [...] de la personne elle-même d'un autre. Et cette attitude, ce serait celle d'un refus de toute considération, de tout respect ou souci pour cette personne. S'il peut y avoir injustice véritable lorsqu'il y a absence volontaire de respect ou de considération pour la volonté, la vie, la liberté ou le bien-être en général d'un autre, ce ne peut être que parce que celui qui se permet de manquer de respect ou de considération pour ces «choses » le fait en sacbant que se permettre cela, en ce moment, c'est se trouver par le fait même à choisir librement - c'est-à-dire tout à fait personnellement - de ne se donner aucune considération, aucun souci, pour la personne elle-même de cet autre (52).

Un tel mépris n'est pas de l'ordre de ce qui peut être spontanément ressenti (une aversion, par exemple) : il est de l'ordre du choisi librement, ce qui suppose une capacité de choisir. Choisir de mépriser quelqu'un, «c'est d'abord croire, irrésistiblement, qu'on pourrait se donner [...] un intérêt personnel pour cette autre personne, puis... ne pas le faire " (105)

Pour une description adéquate des conditions de possibilités d'un agir véritablement libre, on se reportera avec profit au chapitre 4 de Si les marionnettes pouvaient choisir. Qu'il suffise, ici, de distiller en une phrase l'essentiel de la théorie de la liberté de Lane : «[...] la visée principale d'une personne libre ne saurait être que l'entretien et l'expression concrète d'une considération vraiment personnelle pour quelqu'un d'autre" (138). 
Si on conçoit la vie fondamentalement heureuse de la personne comme une vie de "considération mutuelle, c'est-à-dire librement offerte et reçue » (137), on comprend dès lors le lien entre justice, vie heureuse, et liberté. De là à la notion d' "entraide sociale", il n'y a qu'un pas:

La seule chose que les citoyens pourraient attendre d'un gouvernement est donc celle - la seule - que les gouvernants seraient capables de fournir: des politiques destinées à favoriser l'entraide entre tous les concitoyens, c'est-à-dire l'amélioration de la vie en sociétéé, ces politiques devant être en même temps l'expression de la considération authentique des gouvernants eux-mêmes à l'égard de tous (207).

Cet ouvrage de Lane est majeur. Il reprend à neuf une interrogation séculaire à laquelle il répond d'une manière originale et lucide. Avec une argumentation serrée, il prend en compte des positions classiques, des auteurs récents, tant français qu'américains (incidemment, le chapitre 6, principalement consacré à la critique de la théorie de la justice de Rawls, est admirable), bref, il s'agit là d'un livre extrêmement stimulant.

Département de philosophie

Collège de Trois-Rivières 